\title{
A STUDY OF THE OPTICAL PROPERTIES OF PERIPHERAL BLOOD NEUTROPHILS OF HORSES EXPOSED TO TOTAL EXTERNAL $\gamma$-RADIATION
}

\section{T.S. SHEVCHENKO}

All-Russian Research Institute of Radiology and Agroecology, Federal Agency of Scientific Organizations, $109 \mathrm{~km}, \mathrm{Ki}-$ evskoe sh., Obninsk, Kaluga Province, 239032 Russia, e-mail riar@obninsk.org, Shevchenkotatyana@yandex.ru ORCID: Shevchenko T.S. orcid.org/0000-0002-6326-165x

The author declares no conflict of interests

Received April 25, 2016

\section{Abstract}

An important diagnostic test to reveal diseases in agricultural animals is to define the content of formed elements, including neutrophils. Qualitative and quantitative neutrophil characteristics are essential in health assessment and in case of radiation damage of animals due to the radiation induced death of granulocyte progenitors in the bone marrow. Worth noting is a small number of publications on the state of neutrophils in exposed animals, not only in agricultural but also in the laboratory ones. In particular, the literature practically lacks data on the optical properties of neutrophils and the effects on them of the radiation factor. Therefore, the aim of the paper was to study the optical properties of these cells isolated from the peripheral blood of horses exposed to total external $\gamma$-radiation. The absorbancy of horse neutrophil suspension was determined on a spectrophotometer CF-26 (Russia) at $600 \mathrm{~nm}$ and optical path length of $1 \mathrm{~cm}$. The animal blood was taken from the jugular vein prior to irradiation and then on days 1, 3, 5, 7, 10, 15, 20, 25 and 30 after irradiation. The neutrophil suspension was obtained from the peripheral blood by urografin density gradient centrifugation with a specific density of $1.077 \mathrm{~g} / \mathrm{cm}^{3}$. A group of four horses served as control, these were kept in the same conditions as 4 groups of experimental animals, 5 horses each. The latter were exposed to total external $\gamma$-radiation at doses of 2, 3, 4 and $5 \mathrm{~Gy}$. The value of the optical density of neutrophil suspension calculated for $10^{5}$ cells per $1 \mathrm{ml}$, which averages $0.572 \pm 0.023$ relative units, was found to be practically unchangeable in horses exposed to external $\gamma$-radiation in a wide dose range. This is the evidence of stability of the optical properties of neutrophil granulocytes in animals with a radiation damage, which allows photometric investigations of these cells in irradiated horses. The photometric analysis of the suspension of the isolated neutrophils has revealed the following regularities. The optical density of cells in intact horses was $0.235+0.032$ relative units. In the early period of radiation pathology in all groups of the treated animals the value of the neutrophil optical density increased 2.1-2.8 times, then sequentially decreased and increased in the latent period on days 5-10 and fell drastically (up to 10-12 times) in the main phase of radiation sickness on days 20-30. The horses exposed to $\gamma$-radiation at 5 Gy showed noticeable reduction in the parameter (18 times lower) on day 10. The investigations have shown that total exposure to $\gamma$-radiation in a wide dose range results in changes of optical properties of suspension of the isolated neutrophils which is consistent with the dynamics of the neutrophil content in the peripheral blood of horses.

Keywords: horses, total external exposure to $\gamma$-radiation, peripheral blood, neutrophills, optical density, neutrophil content

It is known that an important diagnostic test to reveal diseases in agricultural animals is to define the content of formed elements, including neutrophils [1-4]. Neutrophils (neutrophilic granulocytes) are a factor of nonspecific resistance, providing the first stage of an immune response to bacterial and other pathogens and preceded by a more specific lymphocytic pathogene [5, 6]. These cells are capable of phagocytosis [7-9], but they are also recognized as universal effectors of homeostasis $[10,11]$. Neutrophil is considered as a unique unicellular secretory gland that realizes the effector potential, including secreting soluble products - pro- and anti-inflammatory cytokines, anaphylotoxins and other bactericidal and cytotoxic substances, depending on the performed functions [12- 
14]. Neutrophil granulocytes have receptors for a huge number of endogenous mediators (signal molecules) that trigger certain signal systems that affect specific biochemical processes in the cell [15-17]. They are able to respond to the cytokines exposure by increasing the expression of genes involved in the realization of the immune response and the appearance of receptors inherent in antigenpresenting cells $[18,19]$. Besides, secreting biologically active substances, neutrophilic granulocytes can have a regulatory effect on the function of other immunecompetent cells [20-22]. All this gives neutrophils the ability to quickly respond to the slightest changes in the constancy of the internal environment of the body, which allows us to consider these cells as a kind of "homeostasis mirror".

Neutrophils and their qualitative and quantitative characteristics are important for assessing the health status during radiation damage to animals and radiation-induced death of granulocyte cell precursors in the bone marrow [23]. Of particular interest is the study of these polymorph-nuclear leukocytes in horses animals with specific physiology and metabolism, as well as a special ratio of blood elements with a large number of neutrophils (45-62 \% against 20-35\%, respectively, and 35-45\% in bovine cattle and sheep) [2]. At the same time, there are few studies of the state of neutrophils under radiation effects on the organism of farm animals [24, 25] and other species of mammals [26-31].

The data presented in this study on the evaluation of the neutrophilic pool of peripheral blood of horses and the change in the optical density of the neutrophil suspension in the radiation injury of animals in semi-lethal and sublethal doses at various stages of pathology development significantly supplement the knowledge in this field, since such information is practically absent in the literature.

The aim of the work was to study the optical properties of neutrophils isolated from peripheral blood of horses after the general external action of $\gamma-$ radiation in a wide range of doses.

Techniques. Experiments were performed on 24 horses (outbred mares) at the age of 3-5 years with a body weight of $394 \pm 0.32 \mathrm{~kg}$, which were kept in the vivarium of the All-Russian Research Institute of Radiology and Agroecology (ARRIRA). The ration was balanced according to the norms of the ARRIAH (All-Russian Research Institute of Animal Husbandry, Moscow Province). Control was a group of 4 horses, which were kept under the same conditions as the experimental ones. The animals of four test groups (I, II, III and IV, of 5 heads each) were subjected to a general external action of $\gamma$-radiation at doses of 2, 3, 4 and $5 \mathrm{~Gy}$, respectively, at a dose rate of $1 \mathrm{~Gy} / \mathrm{h}$ at the GUZH-24 unit (Russia) (the radiation source was ${ }^{137} \mathrm{Cs}$ with $\gamma$-quant energy of $0.67 \mathrm{MeV}$ ). Uniformity of irradiation was monitored using a VAJ-18 dosimeter (Germany) equipped with a spherical ionization chamber VAK-253 (Germany). The non-uniformity of the $\gamma$-field did not exceed $15 \%$.

General state, behavior, response to external stressors, appetite, body temperature, pulse and respiratory rate, gastrointestinal tract functionы, body weight dynamics, life expectancy and hematologic indices of animals were controlled by conventional methods.

Peripheral blood were sampled from the jugular vein before and on day $1,3,5,7,10,15,20,25$ and 30 after the total external exposure of $\gamma$-radiation. Anticoagulant was sodium citrate at a final concentration of $0.38 \%$. Neutrophils were isolated by the method of blood sample centrifugation in the gradient of an isodensity substance with $d=1.077 \mathrm{~g} / \mathrm{cm}^{3}$ we developed earlier [32]. The isolated cells were washed by single centrifugation at $200 \mathrm{~g}$ and $20{ }^{\circ} \mathrm{C}$ for 10 minutes in a medium containing $\mathrm{NaCl}, \mathrm{KCl}, \mathrm{K}_{2} \mathrm{HPO}_{4}, \mathrm{MgCl}_{2}$, glucose and 5-N-2(hydroxyethyl) piperazine-N'-2-ethanesulfonic acid $(145 ; 5 ; 0.5 ; 1 ; 3$ and 10 
mmol/1, $\mathrm{pH} 7.4$, respectively) (Merck, Germany).

The total number of white blood cells was counted under the Biolar-2 microscope (Poland) in whole peripheral blood samples, followed by the determination of the percentage of neutrophils in smears [1]. The viability of the isolated neutrophils was controlled in a test with trypan blue (Sigma-Aldrich, USA). Photometric analysis of neutrophil suspensions was performed on a spectrophotometer SF-26 (Russia) at $\lambda=600 \mathrm{~nm}$ and optical path length $1 \mathrm{~cm} \mathrm{[31].}$

The mean $(X)$ and standard errors of the mean $( \pm x)$ are presented. Statistical analysis was performed using Student's $t$-test. Differences between control and test values were considered statistically significant at $\mathrm{p}<0.05$.

Results. The viability of the isolated cell populations of neutrophils, estimated in the trypan blue test, was 92-97\%. Neutrophils are large cells 9-15 $\mu \mathrm{m}$ in size, the surface of which has small roughnesses, small folds, vesicular and rodshaped evaginations [5]. There is evidence that some physical and chemical factors can modify the adhesiveness of neutrophils [24, 33, 34]. Therefore, it was necessary to find out whether the exposure to radiation with a wide range of doses affects the optical properties of neutrophils, since a change in the shape and surface of cells, as well as the formation of cell conglomerates, can alter the light absorption. To do this, the optical density (OD) of the neutrophil suspension was calculated at $10^{5} / \mathrm{ml}$ in horses irradiated at doses of 2, 3, and 4 Gy and in control animals. As it turned out, this indicator was not significantly different in control and test (Table 1). The average $\mathrm{OD}_{600}$ indicators for non-irradiated horses were $0.567 \pm 0.021$ with an average value of $0.572 \pm 0.023$ for all measurements. That is, the corrected value of the optical density of the $10^{5} / \mathrm{ml}$ neutrophil suspension, which practically corresponds to the optical density of one cell, was virtually constant at various times after horse irradiation at doses of 2, 3 and 4 Gy making 0.570-0,600 in most cases (see Table 1).

1. Optical density $\left(\mathrm{OD}_{600}\right.$ per $10^{5}$ cells/ml) of suspension of equine neutrophils isolated from whole peripheral blood as dependent on the dose of external $\gamma$ radiation at different periods after exposure $(X \pm x$, vivarium of the All-Russian Research Institute of Radiology and agroecology, Obninsk)

\begin{tabular}{l|c|c|c|c}
\hline \multirow{2}{*}{ Period, days } & \multicolumn{2}{|c|}{ Dose of external $\gamma$-radiation, Gy } & \multirow{2}{*}{$\begin{array}{c}\text { Non-irradiated } \\
\text { horses }(n=4)\end{array}$} \\
\cline { 2 - 3 } & $2(n=5)$ & $3(n=5)$ & $4(n=5)$ & \\
\hline $\begin{array}{l}\text { Before exposure } \\
\text { (initial index)) }\end{array}$ & $0.565 \pm 0.027$ & $0.573 \pm 0.019$ & $0.582 \pm 0.023$ & $0.567 \pm 0.021$ \\
After exposure: & & & & \\
1 & $0.593 \pm 0.023$ & $0.571 \pm 0.018$ & $0.579 \pm 0.021$ & $0.573 \pm 0.023$ \\
3 & $0.598 \pm 0.019$ & $0.592 \pm 0.021$ & $0.568 \pm 0.017$ & $0.572 \pm 0.018$ \\
7 & $0.614 \pm 0.035$ & $0.597 \pm 0.026$ & $0.592 \pm 0.024$ & $0.578 \pm 0.022$ \\
10 & $0.595 \pm 0.022$ & $0.603 \pm 0.025$ & $0.571 \pm 0.032$ & $0.587 \pm 0.027$ \\
15 & $0.603 \pm 0.027$ & $0.564 \pm 0.017$ & $0.567 \pm 0.026$ & $0.575 \pm 0.019$ \\
20 & $0.562 \pm 0.018$ & $0.581 \pm 0.026$ & $0.585 \pm 0.025$ & $0.588 \pm 0.024$ \\
\hline
\end{tabular}

Thence, the optical properties measured as light absorption at $\lambda=600$ $\mathrm{nm}$ do not undergo significant changes in the development of acute radiation pathology of mild and moderate severity, which allows the photometric analysis of these cells.

The study of the optical density of a suspension of neutrophils isolated from peripheral blood of the horses exposed to $\gamma$-radiation over a wide dose range revealed the following features. The $\mathrm{OD}_{600}$ of the aliquot of the suspension in all non-irradiated horses was $0.235+0.032$ (Table 2).

The exposure of $\gamma$-radiation which causes acute radiation lesion from mild to moderate severity, at the initial period led to a significant increment in optical density of the neutrophil suspension, reaching a 2.1-2.8-fold and 1.1-1.5-fold increase on day 1 and day 3, respectively, when compared to non-irradiated animals. Form day 5 to day 7, when irradiation in doses 2, 3 and $4 \mathrm{~Gy}$, the index 
was a little bit lower then initial one. The dose of 5 Gy caused a 1.6-fold decrease in the index on day 5 and a 1.4-fodl increase on day 7. At 2, 3 and 4 Gy, the optical density, after an increase up to control values and even higher (at $3 \mathrm{~Gy}$ ) on day 10, then declined steadily and repeatedly, being 3.7, 2.9 and 4.5 times lower on day 20, 4.6, 8.9 and 10.5 times lower on day 25, and 7.6, 12.1 and 11.4 times lower on day 30, respectively. In the horses irradiated at $5 \mathrm{~Gy}$, a sharp decrease in the index (by 18 times) on day 10 was marked, after which all the animals died. In this, we did not find a relationship between the optical density of the neutrophil suspension and the dose of $\gamma$-radiation.

2. Optical density $\left(\mathrm{OD}_{600}\right)$ of an aliquot of suspension of equine neutrophils isolated from whole peripheral blood as dependent on the dose of external $\gamma$-radiation at different periods after exposure ( $X \pm x$, vivarium of the All-Russian Research Institute of Radiology and Agroecology, Obninsk)

\begin{tabular}{|c|c|c|c|c|c|}
\hline \multirow{2}{*}{ Period, days } & \multirow{2}{*}{ Control } & \multicolumn{4}{|c|}{ Dose of external $\gamma$-radiation, Gy } \\
\hline & & $2(n=5)$ & $3(n=5)$ & $4(n=5)$ & $5(n=5)$ \\
\hline Before exposure & $0.232 \pm 0.017$ & $0.228 \pm 0.047$ & $0.230 \pm 0.019$ & $0.251 \pm 0.039$ & $0.234 \pm 0.022$ \\
\hline \multicolumn{6}{|l|}{ After exposure: } \\
\hline 1 & $0.227 \pm 0.028$ & $0.615 \pm 0.047^{*}$ & $0.650 \pm 0.099^{*}$ & $0.534 \pm 0.480^{*}$ & $0.585 \pm 0.058^{*}$ \\
\hline 3 & $0.234 \pm 0.025$ & $0.253 \pm 0.055$ & $0.334 \pm 0.055^{*}$ & $0.296 \pm 0.052$ & $0.323 \pm 0.037^{*}$ \\
\hline 5 & $0.222 \pm 0.018$ & $0.169 \pm 0.034$ & - & $0.132 \pm 0.024^{*}$ & $0.150 \pm 0.056^{*}$ \\
\hline 7 & $0.247 \pm 0.019$ & $0.174 \pm 0.030$ & $0.202 \pm 0.063$ & $0.171 \pm 0.018^{*}$ & $0.318 \pm 0.057^{*}$ \\
\hline 10 & $0.235 \pm 0.022$ & $0.221 \pm 0.035$ & $0.339 \pm 0.060$ & $0.200 \pm 0.041$ & $0.013 \pm 0.004^{*}$ \\
\hline 15 & $0.228 \pm 0.017$ & $0.146 \pm 0.025^{*}$ & $0.173 \pm 0.048$ & $0.166 \pm 0.048^{*}$ & - \\
\hline 20 & $0.218 \pm 0.014$ & $0.061 \pm 0.012^{*}$ & $0.079 \pm 0.023^{*}$ & $0.056 \pm 0.014^{*}$ & - \\
\hline 25 & $0.229 \pm 0.013$ & $0.050 \pm 0.006^{*}$ & $0.026 \pm 0.007^{*}$ & $0.024 \pm 0.004 *$ & - \\
\hline 30 & $0.228 \pm 0.016$ & $0.030 \pm 0.004^{*}$ & $0.019 \pm 0.004 *$ & $0.022 \pm 0.003^{*}$ & - \\
\hline
\end{tabular}

Thus, the total external exposure of horses to $\gamma$-radiation in sub-lethal and semi-lethal doses led to radiation lesion of mild and moderate severity, which was accompanied by an increase in the optical density of the neutrophil suspension during initial period, then this index sequentially decreased and increased in the latent period and sharply decreased in the main phase of radiation sickness from day 20 to day 30 .

In the photometric study of neutrophils, it has been suggested that the optical density of the cell suspension reflects their quantity in peripheral blood of animals. For clarification, we compared the data on the optical density of the aliquot of the neutrophil suspension and the neutrophil count in the peripheral blood of irradiated and non-irradiated horses, estimated by the traditional hematological method.

3. The neutrophil count in blood and optical density of the aliquot of suspension of equine neutrophils isolated from blood of irradiated ( $3 \mathrm{~Gy}$ ) and non-irradiated horses ( $X \pm x$, vivarium of the All-Russian Research Institute of Radiology and Agroecology, Obninsk)

\begin{tabular}{|c|c|c|c|c|}
\hline \multirow{2}{*}{ Period, days } & \multicolumn{2}{|c|}{ Optical density, $\mathrm{OD}_{600}$} & \multicolumn{2}{|c|}{ Neutrophils, $\times 10^{9} / 1$} \\
\hline & control $(n=4$ & experimental $(n=5)$ & control $(n=4)$ & experimental $(n=5)$ \\
\hline \multirow{2}{*}{\multicolumn{5}{|c|}{$\begin{array}{l}\text { Before exposure } \\
\text { (initial index)) } \\
\text { After exposure. }\end{array}$}} \\
\hline & & & & \\
\hline 1 & $0.226 \pm 0.11$ & $0.650 \pm 0.099^{*}$ & $12.7 \pm 1.3$ & $41.1 \pm 7.2 *$ \\
\hline 3 & $0.243 \pm 0.08$ & $0.334 \pm 0.155$ & $13.4 \pm 2.2$ & $12.1 \pm 5.3$ \\
\hline 7 & $0.235 \pm 0.09$ & $0.202 \pm 0.063$ & $11.8 \pm 2.6$ & $10.3 \pm 3.2$ \\
\hline 10 & $0.244 \pm 0.13$ & $0.339 \pm 0.060$ & $12.9 \pm 1.8$ & $13.7 \pm 6.4$ \\
\hline 20 & $0.238 \pm 0.23$ & $0.079 \pm 0.023^{*}$ & $13.3 \pm 1.9$ & $4.6 \pm 0.9^{*}$ \\
\hline 25 & $0.231 \pm 0.29$ & $0.026 \pm 0.007 *$ & $12.8 \pm 2.1$ & $1.5 \pm 0.7^{*}$ \\
\hline * Differe & ndex are statisti & ly significant at $\mathrm{p}<0.05$. & & \\
\hline
\end{tabular}

In non-irradiated horses, the optical density of the aliquot of the suspen- 
sion was $0.230 \pm 0.190$ (Table 3). After a general external exposure to $\gamma$-radiation at a dose of $3 \mathrm{~Gy}$, radiation lesion was developed, which was accompanied by a 2.8-fold increment in the optical density of the aliquot of the neutrophil suspension on day 1 after irradiation, a decrement almost to the control values on days $3-10$, and a 2.9-fold decrease on day 20, if compared to the initial indexes. The corresponding index in the control animals remained within the initial values throughout the study. At the same time, the peripheral blood neutrophil counts in irradiated horses changed in a similar manner (see Table 3). In non-irradiated horses, the counts averaged $(12.9 \pm 0.8) \times 10^{9} / 1$ and remained practically unchanged for 20 days. In horses subjected to a general external exposure to $\gamma$ radiation at $3 \mathrm{~Gy}$, the neutrophil count in peripheral blood increased 3.2 times on day 1 compared to the initial index, almost decreasing to the values noted in non-irradiated animals from day 3 to day 10 (see Table 3). On days 20 and 25, the number of these cells in the blood decreased 2.8 and 8.6 times, respectively, compared to the initial level. Hence, the results of a hematological assessment of peripheral blood neutrophils in irradiated horses indicated neutrophilia on day 1 , caused by abortive cell ejection from the bone marrow, and neutropenia on days 20-25 with radiation-induced depletion of the granulocyte precursor pool in bone marrow.

Thus, the number of neutrophils in the peripheral blood counted directly under the microscope, and the optical density of the isolated neutrophil suspension changed after animal irradiating in a similar manner. The values of both parameters increased 3.2 and 2.8 times, respectively, on day 1, did not differ from the initial values on days 7-10, decreased 2.8 and 2.9 times on day 20 , and lowered 8.6 and 8.9 times on day 25 .

It should be noted that good correlation was observed between the recorded parameters at all periods after irradiation. Proceeding from such a single-type dynamics, it can be concluded that the use of photometric analysis of isolated neutrophil suspensions can be admissible when studying the changes in their count in horse blood.

Neutrophils, more precisely, the precursors of granulocytes, of mammals normally mature in the bone marrow for 8-12 days. Then they leave in the peripheral blood, where they stay 8-10 hours, then they enter different tissues and, after 3-5 days, undergo spontaneous apoptosis (programmed cell death) [35-38] or netosis [39-43]. External exposure to $\gamma$-radiation in sub-lethal and semi-lethal doses causes the death of granulocyte precursors in bone marrow, which determines the decrease in the peripheral blood neutrophil count after day 12 [23]. Our studies showed a sharp decrease in the optical density of the neutrophil suspension in horses of groups I, II and III, and on day 10 in group IV during this period (form day 20 to day 30). In other words, the main phase of radiation pathology in horses subjected to external $\gamma$-radiation at doses from sub-lethal to semi-lethal is characterized by a significant 2.9-18.0-fold decrease in the optical density of the neutrophil suspensions. The maximum decrease was noted on day 10 in the animals exposed to a semi-lethal dose $(5 \mathrm{~Gy})$. It should be noted that at sub-lethal doses from 2 to $4 \mathrm{~Gy}$, the optical density of neutrophil suspensions did not actually differ for the period from day 7 to day 30 . When exposed to a semi-lethal dose, the dynamics was completely different, showing an increase on days 1-3, a decrease below control on day 5, a 1.4-fold increase on day 7, and a sharp 18-fold decrease on day 10. That is, during the main phase of mild and moderate radiation pathology, which is accompanied by a significant decrease in the optical density of isolated blood neutrophils, practically corresponding to a decrease in their counts in the peripheral blood, it is possible to predict with confidence the emergence and strengthening of existing infectious processes in 
the body. Additionally, there is reason to expect that a 10-12-fold reduction in pool of blood neutrophilic granulocytes in irradiated animals in this period will cause a change of neutrophils, which are the main links of the immune response. This will lead to violation of their regulatory influence on the functions of other immune competent cells due to a significantly reduced secretion of cytokines and other bioactive substances, even at sub-lethal $\gamma$-radiation.

So this research has shown that general external exposure of horses to $\gamma$ radiation under the studied doses leads to a change in the optical density of the suspension of isolated peripheral blood neutrophils, which is consistent with the dynamics of the count of these cells in the peripheral blood. The optical density of the neutrophil suspensions can be used in veterinary practice for express evaluation of the pool of neutrophilic granulocytes in peripheral blood of animals.

\section{R E F EREN CES}

1. Ko nd rakhin I.P., A rk hip ov A.V., Le v c he n k o V.I. Metody veterinarnoi klinicheskoi laboratornoi diagnostiki [Methods of veterinary clinic laboratory diagnostics]. Moscow, 2004 (in Russ.).

2. Mis hanin Yu.F., M is han in M.Yu. Prakticheskaya veterinariya [Practical veterinary medicine]. Rostov-na-Donu, 2002 (in Russ.).

3. $\mathrm{N}$ a z a re $\mathrm{nk}$ o G.I., K is h k u n A.A. Klinicheskaya otsenka rezul'tatov laboratornykh issledovanii [Clinical evaluation of laboratory results]. Moscow, 2005 (in Russ.).

4. K is h k n A.A. Rukovodstvo po laboratornym metodam diagnostiki [Methods of laboratory diagnostics - guidance]. Moscow, 2013 (in Russ.).

5. P in e gi n B.V., M a y a s k i i A.N. Immunologiya, 2007, 28(6): 374-382 (in Russ.).

6. Y a rili n A.A. Immunologiya [Immunology]. Moscow, 2010 (in Russ.).

7. G a r c i a-G a r c i E. Molecular mechanisms of phagocytosis. Landes Vioscience, Georgetown, Texas, 2005.

8. Robinson J.M. Reactive oxygen species in phagocytic leukocytes. Histochemistry and Cell Biology, 2008, 130(2): 281-297.

9. S e g a 1 A.W. How neutrophils kill microbes. Ann. Rev. Immunol., 2006, 23: 197-223.

10. Medical Immunology. V. Gabriel (ed.). Taylor \& Francis, London, 2007.

11. Hicks A.M., Willingt on M.C., D u W. Effector mechanism of the anticancer immune responses of macrophages in SR/CR mice. Cancer Immunity, 2006, 6: 1-9.

12. Abakumova T.V., Antoneeva I.I., Gening T.P., Gening S.O., Dolgov a D.R., F o m i n a A.V. Patologicheskaya fiziologiya i eksperimental'naya terapiya, 2014, 4: 8690 (in Russ.).

13. Dolgushin I.I., S avo chkina A.Yu. Allergologiya i immunologiya, 2015, 2: 210-212 (in Russ.).

14. Zh ou J., Perelman J.M., Kolos ov V.P., Z h ou X. Neutrophil elastase induces MUC5AC secretion via protease activated receptor 2. Molecular and Cellular Biochemistry, 2013, 377(1-2): 75-85 (doi: 10.1007/s11010-013-1572-3).

15. Kupchik Y.M., Barchad-Avitzur O., B en-Chaim Y., Parnas L., Parnas H., Wess J. A novel fast mechanism for GPCR-mediated signal transduction - control of neurotransmitter release. Journal of Cell Biology, 2011, 192(1): 137-151 (doi: 10.1083/jcb.201007053).

16. Wang N., De Bock M., Decrock E., Bol M., Gadicherla A.A., Leybaert L., Vinken M., Rogiers V., Bukauskas F.F., Bultynck G. Paracrine signaling through plasma membrane hemichannels. Biochimica et Biophisica Acta. Biomembranes, 2013, 1828(1): 35-50 (doi: 10.1016/j.bbamem.2012.07.002).

17. B a roja-Mazo A., B arbera-Cremades M., Pelegrin P. The participation of plasma membrane hemichannels to purinergic signaling. Biochimica et Biophisica Acta. Biomembranes, 2013, 1828(1): 79-93 (doi: 10.1016/j.bbamem.2012.01.002).

18. Nesterova I.V., Shvyd chenko I.N., Romenskaya V.A. Allergologiya i immunologiya, 2008, 9(4): 432-436 (in Russ.).

19. Cass at e 11 a M.A., Mosna F., Miche 1 etti A. Toll-like receptor-3-activated human mesenchymal stromal cells significantly prolong the survival and function of neutrophils. Stem. Cells, 2011, 29(6): 1001-1011.

20. K h a i t o v R.M. Immunologiya [Immunology]. Moscow, 2011 (in Russ.).

21. D i e b o ld B.A., B o k o ch G.M. Rho GTPase and the control of the oxidative burst in polymorphonuclear leukocytes. Current Topics of Microbiology and Immunology, 2005, 291: 91-111.

22. Fernandes M.J., Rollet-Labe 11 e E., P a r e G. CD11b associates with high-density, detergent resistant membranes in human neutrophils. Biochem. J., 2006, 393: 351-359. 
23. Ku d ry a s h o v Yu.B. Radiatsionnaya biofizika (ioniziruyushchie izlucheniya) [Radiobiophysics (ionizing radiation)]. Moscow, 2004 (in Russ.).

24. Akleev A.A., Grebenyuk A.N., Gluminina O.A. Vestnik Chelyabinskogo gosudarstvennogo universiteta, Biologiya, 2013, 7(298): 91-93 (in Russ.).

25. Grebenyuk A.N. Sostoyanie neitrofilov pri radiatsionnykh vozdeistviyakh. Avtoreferat doktorskoi dissertatsii. [Neutrophils affected by radiation. DSci. Thesis]. St. Petersdurg, 2002 (in Russ.).

26. I s a m o v N.N., I s a mov N.N. (Jr.) Radiobiologiya i radioekologiya loshadei /Pod redaktsiei R.M. Aleksakhina [Radiobiology and radioecology of horses. R.M. Aleksakhin (ed.)]. Obninsk, 2009 (in Russ.)

27. Me o S.A., A 1 Dress A.M., Z ad i S.Z., A 1 Da mon S., Al- Tuwauri A.S. Hazards of X-ray radiation on quantitative and phagocytic function of polymorphonuclear neutrophils in X-ray technicians. J. Occup. Health, 2006, 48: 88-92.

28. Wilkins R.C., Wilkinson D., Macharaj H.P., Bellier P.V., Cybuiski M.B., $\mathrm{McLe}$ a J.R. Differential apoptotic response to ionizing radiation in sub population of human white blood cells. Mutat. Res., 2002, 513(1-2): 27-36.

29. Lat ifynia A., Vojgani M., Gharagozlou M.J., Sharifian R. Neutrophil finction (innate immunity) during ramadan. J. Auub. Med. Coll. Abbottabad, 2009, 21(4): 111-115.

30. Lat ifynia M.Y., Kalamzadeh A., Abofazeli T., Nuraie M., Khransarii N. Phagocyte finctions of human subjects living in high level of natural radiation areas in Iran. J. Auub. Med. Coll. Abbottabad, 2012, 24(3-4): 177-179.

31. Shevchenko T.S., Shevchenko A.S. [Photometric parameters and protein content in blood cells of intact farm animals and the individuals exposed to radiation]. Sel'skokhozyaistvennaya biologiya [Agricultural Biology], 1999, 4: 114-118 (in Russ.).

32. $\mathrm{S} \mathrm{h} \mathrm{e} \mathrm{v} \mathrm{che} \mathrm{nko}$ T.S. Method for isolation of cellular populations from peripheral blood of farm animals. Sel'skokhozyaistvennaya biologiya [Agricultural Biology], 2007, 6: 123-126 (in Russ.).

33. Gil-Villa A.M., N orling L.V., S e rh a n C.N., C o rde ro D. Aspirin triggered-lipoxin $\mathrm{A}(4)$ reduces the adhesion of human polymorphonuclear neutrophils to endothelial cells initiated by preeclamptic plasma. Prostaglandins Leukot. Essent. Fatty Acids, 2012, 87(4-5): 127-134 (doi: 10.1016/j.plefa.2012.08.003).

34. Overbeek S.A., Kle injan M., Hen ricks P.A.J., Ka mp V.M., Georgiou N.A., Garsse $n$ J., Kraneveld and A.D., Folkerts G. Chemo-attractant N-acetyl prolineglycine-proline induces CD11b/CD18-dependent neutrophil adhesion. Biochimica et Biophisica Acta, 2012, 1830(1): 2188-2193.

35. M a es him a Y., Maki no H. Molecular mechanism of cell injury. Contrib. Nephrol., 2003, 139: $32-43$.

36. Luo H.R., Loison F. Constitutive neutrophil apoptosis mechanisms and regulation. $J$. Haematology, 2008, 83(4): 288-295.

37. M y ad as T.N., Ts ok os G.C., Tsubo i N. Mechanisms of immune complex-mediated neutrophil recruitment and tissue injury. Circulation, 2009, 120(20): 2012-2024.

38. Zhavoronok T.V., Stepovaya Ye.A., Ryazantseva N.V., Petina G.V., $\mathrm{S}$ t a rik o v Yu.V., A g e e a T.S. Influence of oxidative stress on redox-state and peripheral blood heterophilic leukocytes apoptotic program realization. European Journal of Natural History, 2007, 6: 63-64.

39. B ri n k man V., Re cha rd U., Go os man n C. Neutrophil extracellular traps kill bacteria. Science, 2004, 303: 1532-1535.

40. Brinkman V., Zychlinsky A. Beneficial suicide: why neutrophils die to make NETs. Nature Rev., 2007, 5: 577-582.

41. Fuches T.A., Abed U., Goos man $n$ C. Novel cells death program leads to neutrophil extracellular traps. J. Cell Biol., 2007, 176(2): 231-241.

42. J e n n e C.N. Neutrophils recruited to sites of infection protect from virus challenge by releasing neutrophil extracellular traps. Cell Host and Microbe, 2013, 13: 169-180.

43. Gupta A.K., Joshi M.B., Philippova M. Activated endothelial cells induce neutrophil extracellular traps and are susceptible to NETosis-mediated cell death. FEBS Lett., 2010, 584: 3193-3197. 